\title{
DETERMINATION OF RUPTURE DURATION AND STRESS DROP FOR EARTHQUAKES IN SOUTHERN CALIFORNIA
}

\author{
By Arthur Frankel and Hiroo Kanamori
}

\begin{abstract}
A simple technique is developed for determining the rupture duration and stress drop of earthquakes between magnitudes 3.5 and 4.0 using the time between the $P$-wave onset and the first zero crossing $\left(\tau_{1 / 2}\right)$ on seismograms from local seismic networks. This method is applied to $\mathbf{1 0}$ main shocks in southern California to investigate regional variations in stress drop. The initial pulse widths of 65 foreshocks or aftershocks of these events were measured. Values of $\tau_{1 / 2}$ for small earthquakes below about magnitude 2.2 are generally observed to remain constant with decreasing magnitude in four sequences studied. The relative pulse width of a particular main shock $(M \geqq 3.5)$ at a given station is found to be correlated with the relative pulse width of its aftershocks recorded at that station. These observations are interpreted to signify that the waveforms of these small events $(M \leqq 2.2)$ are essentially the impulse response of the path between the source and receiver. Values of $\tau_{1 / 2}$ determined from small foreshocks and aftershocks are, therefore, subtracted (in effect deconvolved) from those of each main shock to obtain an estimate of the rupture duration of the main shock which is corrected for path effects.

Significant variations in rupture duration and stress drop are observed for the main shocks studied. Aftershock locations and azimuthal variations in $\tau_{1 / 2}$ both indicate that the rupture zone of one earthquake expanded unilaterally. A factor of $\mathbf{1 0}$ variation in stress drop is calculated for two adjacent events of similar seismic moments occurring $1 \mathrm{hr}$ apart on the San Jacinto fault system. The first event in this pair had the highest stress drop of the events studied ( 860 bars) and was followed within 8 months by a magnitude 5.5 earthquake $2 \mathrm{~km}$ away.
\end{abstract}

\section{INTRODUCTION}

The measurement of seismic stress drop constitutes one of the few methods for constraining estimates of the tectonic stress at depth. Although earthquake stress drops cannot specify the absolute level of tectonic stress, they represent a lower bound. Areas containing earthquakes with relatively high stress drops are presumably regions of comparatively large tectonic stress. The determination of spatial and temporal variations in stress drop would improve our understanding of the accumulation of tectonic stress and may have application to earthquake prediction. The seismic stress drop is one of the parameters which determines the level of accelerations produced by an earthquake, and regional variations in stress drop could have importance to seismic risk analysis.

This paper presents a simple technique for estimating the rupture duration and hence stress drop of earthquakes between about magnitudes 3.5 and 4.0 using seismograms from local seismic networks. Routine determination of stress drop for the large numbers of earthquakes recorded by short-period networks $\left(f_{0} \approx 1 \mathrm{~Hz}\right.$ ) could provide substantial information on the temporal and spatial variations of the tectonic stress field.

We measure the time between the $P$-wave onset and the first zero crossing directly from the seismogram (denoted as $\tau_{1 / 2}$ ) to estimate the rupture duration of earthquakes greater than magnitude 3.4 in southern California. The seismograms were collected by the array of short-period seismometers operated in southern California 
jointly by the U.S. Geological Survey (USGS) and the California Institute of Technology (CIT). The initial pulse width on the seismogram is a function of the rupture duration, the instrumental response, and the broadening caused by the apparent attentuation of the path. The term "apparent attenuation" refers to the loss of high-frequency energy relative to low-frequency energy by either intrinsic dissipation in the crustal rocks or by scattering from heterogeneities.

The essential problem in stress drop determination that we address in this paper is the effect of the source-receiver path on the initial pulse width of the seismogram. We seek to compare stress drop estimates from earthquakes in a variety of tectonic regimes, and we require a simple method that corrects for the propagation effects between each source-station pair. This task is also complicated by the fact that the network stations are usually separated from the earthquakes by a distance of several source depths. For such stations, the first arrival may not represent the direct wave but may consist of the interference of diving waves refracted by positive velocity gradients in the crust (see Červený, 1966).

The influence of apparent attenuation on high-frequency seismic energy $(f>5$ $\mathrm{Hz}$ ) is poorly understood, and its severity is debated. Recent evidence implies that large amounts of apparent attenuation may occur at shallow depths $(0$ to $3 \mathrm{~km})$ beneath the receiving sites, a process referred to as the site response. This site response can produce corner frequencies in displacement spectra and pulse durations in the waveforms of microearthquakes which are unrelated to source duration. Frankel (1982) reported corner frequencies for microearthquakes in the northeastern Caribbean that were characteristic of the receiving sites. Hanks (1982) observed that the acceleration spectra derived from strong motion records rapidly fall off above a certain frequency, which he denoted as $f_{\max }$. He noted that $f_{\max }$ was related to site characteristics for recordings of aftershocks in Oroville, California. Andrews (1982) reported spectral differences dependent on receiver site for earthquakes in Mammoth Lakes. These studies suggest that it is necessary to correct for the site response before using spectra or pulse widths to estimate the source dimensions of small earthquakes.

In the first part of this paper, we summarize our observations on the dependence of initial pulse width on magnitude in three main shock-aftershock sequences and one swarm in southern California. We find that $\tau_{1 / 2}$ usually decreases to a minimum value that remains constant as the magnitude of the earthquake decreases below about 2.2. These minimum pulse widths differ between stations at comparable distances from each of these sequences. We interpret these minimum pulse widths as being produced solely by propagation effects.

One of the key points we wish to demonstrate is that the source duration can only be determined for earthquakes whose rupture times are sufficiently long to be separated from the pulse broadening caused by the path. Therefore, we limit our investigation to the source parameters of earthquakes of magnitude 3.5 and greater. Unfortunately, the high gain and limited dynamic range of the seismic network cause the seismograms of such events to be severely clipped. This clipping occurs during the modulation of the signal at the seismometer site before it is transmitted by radio or telephone line to the central recording site. Although the seismometer accurately tracks the ground motion of these larger events, the voltage controlled oscillator (VCO) has a limited range of frequency modulation. Ellis and Lindh (1976) demonstrated that the zero crossings of clipped seismograms from the USGS network instrumentation accurately reflect the zero crossings of the unclipped seismometer output. O'Neill and Healy (1973) have used $\tau_{1 / 2}$ from clipped records 
of local network stations to estimate the source parameters of earthquakes in central California and Colorado.

In this paper, we use the waveforms of small aftershocks and foreshocks $(M<$ 2.4) as empirical Green's functions to correct for the effects of the path and the instrument on the initial pulse width of the larger events $(3.5 \leqq M<4.0)$ studied. We then estimate the rupture duration and stress drop of 10 main shocks in southern California. We felt that the zero crossings of events greater than magnitude 4.0 may represent subevents and that such earthquakes would not be appropriate for this study. The technique presented in this paper reveals that significant differences in stress drop occur in southern California for events in the magnitude range studied.

\section{DATA}

We measured the $\tau_{1 / 2}$ 's for 11 main shocks $(M \geqq 3.5)$ and 65 smaller events that accompanied them. The pertinent data are listed in Tables 1 and 2 . The locations of the main shocks and stations used in this study are shown in Figure 1. We limited our study to stations within $70 \mathrm{~km}$ of the earthquakes. $\tau_{1 / 2}$ was measured only if the foreshock/aftershock waveform had the same first motion as the main shock. Only waveforms with relatively impulsive $P$ waves were analyzed.

Each station of the southern California network (SCARLET) consists of a vertical seismometer with a $1-\mathrm{Hz}$ natural period. At the frequencies of interest to this study $(>5 \mathrm{~Hz})$, the output of the seismometer is flat to velocity. Figure 2 shows the response of the system (standard USGS configuration) to an impulse of ground displacement determined from the response characteristics given by Archambeau (1979). The value of $\tau_{1 / 2}$ measured from the seismogram is, to within $0.012 \mathrm{sec}$, equivalent to the $\tau_{1 / 2}$ of the ground velocity. At the central recording site, the signals are recorded on analog magnetic tape and on digital tape when an event detector is triggered (see Johnson, 1979). The digital system samples the waveforms at 50 samples/sec.

The determination of the relative magnitude of these events was complicated by the limited dynamic range of the network. For the events less than magnitude 3 , we measured the peak-to-peak amplitude of the first cycle of the $P$ wave from one to three unclipped stations for each event. The relative magnitude of each event was calculated directly from the $\log$ of the ratio of the $P$-wave amplitudes averaged over these stations. For the events accompanying main shock number 11, the magnitudes were estimated from values of the maximum $S$-wave amplitudes. Magnitudes listed for the main shocks represent the local magnitudes determined from the maximum amplitude of the $S$ wave recorded on Wood-Anderson seismometers.

A change in the instrumentation at the central recording site during late 1978 necessitated the use of seismograms played back from both the digital and analog tapes. The pulse widths of events prior to late 1978 (events 1 through 5 and their accompanying earthquakes) were read directly from playbacks of the digital recordings. In late 1978, antialiasing filters were installed at the recording site. This produces the impulse response shown in Figure 2 as the modified USGS configuration. These filters altered the signals that entered the digital recording system but were not applied to the signals recorded on analog tape. We found that the addition of the antialiasing filter severely distorts the zero crossings of the clipped seismograms. Therefore, we utilized playbacks from the analog tapes to measure the pulse widths of the main shocks after 1978.

The measurement of $\tau_{1 / 2}$ for the smaller events after 1978 presented another 
TABLE 1

Magnitudes and Initial Pulse Widths for Events Studied

\begin{tabular}{|c|c|c|c|c|c|c|c|c|c|c|}
\hline \multirow[t]{2}{*}{ Event No } & \multirow[t]{2}{*}{ Date } & \multirow[t]{2}{*}{ Time (UTC) } & \multirow[t]{2}{*}{ Magnitude } & \multicolumn{4}{|c|}{$T^{1 / 2}$ (sec) } & \multirow{2}{*}{\multicolumn{2}{|c|}{ MDA }} & \\
\hline & & & & PSP & RAY & RMR & INS & & & \\
\hline \multirow[t]{6}{*}{1} & 22 Sept 1977 & $9: 41$ & 3.5 & 0.09 & 0.13 & 0.11 & 0.12 & 0.125 & 0.15 & \\
\hline & & $9: 30$ & 2.0 & 0.05 & 0.075 & 0.055 & 0.085 & 0.065 & & \\
\hline & & $9: 54$ & 2.8 & 0.05 & 0.10 & 0.08 & 0.09 & & 0.11 & \\
\hline & & $18: 29$ & 2.1 & 0.05 & 0.07 & 0.05 & 0.085 & 0.06 & 0.10 & \\
\hline & 23 Sept. 1977 & $00: 08$ & 13 & 0.05 & & 0.055 & & & & \\
\hline & & & & SIL & RAY & $\mathrm{CKC}$ & & & & \\
\hline \multirow[t]{10}{*}{2} & 5 Feb. 1978 & $9: 53$ & 3.8 & 0.16 & 0.15 & 0.14 & & & & \\
\hline & 4 Feb. 1978 & $20: 48$ & 1.5 & 0.08 & 0.09 & & & & & \\
\hline & 5 Feb. 1978 & $4: 25$ & 2.3 & 0.095 & 0.10 & & & & & \\
\hline & & $4: 50$ & 2.1 & 0.105 & 0.09 & 007 & & & & \\
\hline & & $8: 41$ & 1.5 & 0.08 & & & & & & \\
\hline & & $11: 14$ & 2.1 & & 0.085 & 0.065 & & & & \\
\hline & & $20: 03$ & 1.8 & 0.085 & 0.07 & & & & & \\
\hline & & $22: 43$ & 1.3 & 0.08 & & & & & & \\
\hline & 12 Feb. 1978 & $14: 55$ & 1.7 & 0.085 & & & & & & \\
\hline & & & & SIL & RAY & INS & TPC & $\mathrm{RDM}$ & SDW & $\mathrm{KEE}$ \\
\hline \multirow{11}{*}{$\eta p p y$} & 29 Apr. 1978 & $4: 03$ & 3.8 & 0.20 & 0.14 & 0.16 & 0.22 & 0.19 & 0.21 & 0.11 \\
\hline & & $4: 11$ & 1.4 & 0.07 & & & & & & \\
\hline & & $4: 29$ & 2.5 & 0.07 & 0.07 & 0.09 & & 0.065 & 0.065 & \\
\hline & & $4: 31$ & 2.4 & 0.075 & 0.075 & 0.09 & 0.125 & 0.07 & 0.06 & 0.06 \\
\hline & & $6: 18$ & 1.6 & 0.07 & 0.065 & 0.075 & & & & \\
\hline & & $9: 13$ & 1.8 & 0.07 & 0.07 & 0.085 & & & & \\
\hline & & $10: 32$ & 1.5 & 0.065 & 0.06 & 0.065 & & & & \\
\hline & & $10: 48$ & 1.5 & 0.07 & 0.075 & 0.065 & & & & \\
\hline & & $11: 17$ & 1.8 & 0.07 & 0.065 & 0.075 & & & & \\
\hline & & $13: 19$ & 2.1 & 0.08 & 0.075 & 0.08 & & 0.065 & & \\
\hline & & $13: 21$ & 1.8 & 0.07 & 0.06 & 0.07 & & & & \\
\hline
\end{tabular}




\begin{tabular}{|c|c|c|c|c|c|c|c|c|}
\hline & \multirow[t]{2}{*}{30 Apr. 1978} & $2: 48$ & 1.8 & 0.065 & 0.065 & \multicolumn{3}{|l|}{0.065} \\
\hline & & 18:06 & 1.7 & 0.065 & 0065 & \multicolumn{3}{|l|}{0.07} \\
\hline & 7 May 1978 & $23: 30$ & 1.7 & 0.07 & 0.07 & \multicolumn{3}{|l|}{0.08} \\
\hline & 17 May 1978 & $6: 43$ & 1.6 & 0.075 & & & & \\
\hline & & & & MOV & RMR & \multicolumn{3}{|l|}{ SMO } \\
\hline \multirow[t]{3}{*}{4} & $5 \quad$ July 1978 & $10: 47$ & 3.7 & 0.13 & 0.18 & \multicolumn{3}{|l|}{0.09} \\
\hline & & $10: 52$ & 2.1 & 0.07 & 0.11 & \multicolumn{3}{|l|}{0.04} \\
\hline & & & & $\mathrm{CKC}$ & SME & \multicolumn{3}{|l|}{ PEM } \\
\hline \multirow[t]{5}{*}{5} & 11 Aug. 1978 & $00: 47$ & 3.9 & 0.16 & 0.12 & \multicolumn{3}{|l|}{0.21} \\
\hline & & $21: 26$ & 1.9 & & 0.05 & \multicolumn{3}{|l|}{0.105} \\
\hline & 12 Aug. 1978 & $15: 40$ & 1.5 & 0.065 & 0.065 & \multicolumn{3}{|l|}{0.115} \\
\hline & 16 Aug. 1978 & $17: 04$ & 2.0 & 0.07 & 0.075 & \multicolumn{3}{|l|}{0.11} \\
\hline & & & & SMO & $\mathrm{KEE}$ & $\mathrm{COY}$ & PSP & RAY \\
\hline \multirow[t]{3}{*}{6} & 2 July 1979 & $11: 51$ & 3.8 & 0.07 & 0.08 & 0.085 & 0.08 & 0.12 \\
\hline & & $12: 15$ & 1.4 & 0.045 & 0.05 & 0.06 & 0.055 & \\
\hline & & $12: 41$ & 1.4 & 0.035 & & & & \\
\hline \multirow[t]{4}{*}{7} & 2 July 1979 & $12: 42$ & 3.6 & 0.09 & 0.14 & 0.115 & 0.095 & \multirow{3}{*}{$\begin{array}{l}0.15 \\
0.095\end{array}$} \\
\hline & & $12: 45$ & 2.3 & & & & & \\
\hline & & $12: 49$ & 2.1 & & 0.075 & 0.07 & 0.065 & \\
\hline & & & & BLU & LJB & $\mathrm{ADL}$ & $\mathrm{RDM}$ & \\
\hline \multirow[t]{4}{*}{8} & 28 Aug. 1979 & $8: 57$ & 3.9 & 0.085 & 0.09 & \multirow{4}{*}{$\begin{array}{l}0.095 \\
0.06\end{array}$} & \multicolumn{2}{|l|}{0.13} \\
\hline & 29 Aug. 1979 & $14: 19$ & 2.5 & & 0.045 & & 0.09 & \\
\hline & 30 Aug. 1979 & $2: 18$ & 2.1 & 0.05 & 0.045 & & & \\
\hline & 3 Sept. 1979 & $00: 06$ & 2.4 & 0.055 & 0.05 & & & \\
\hline
\end{tabular}




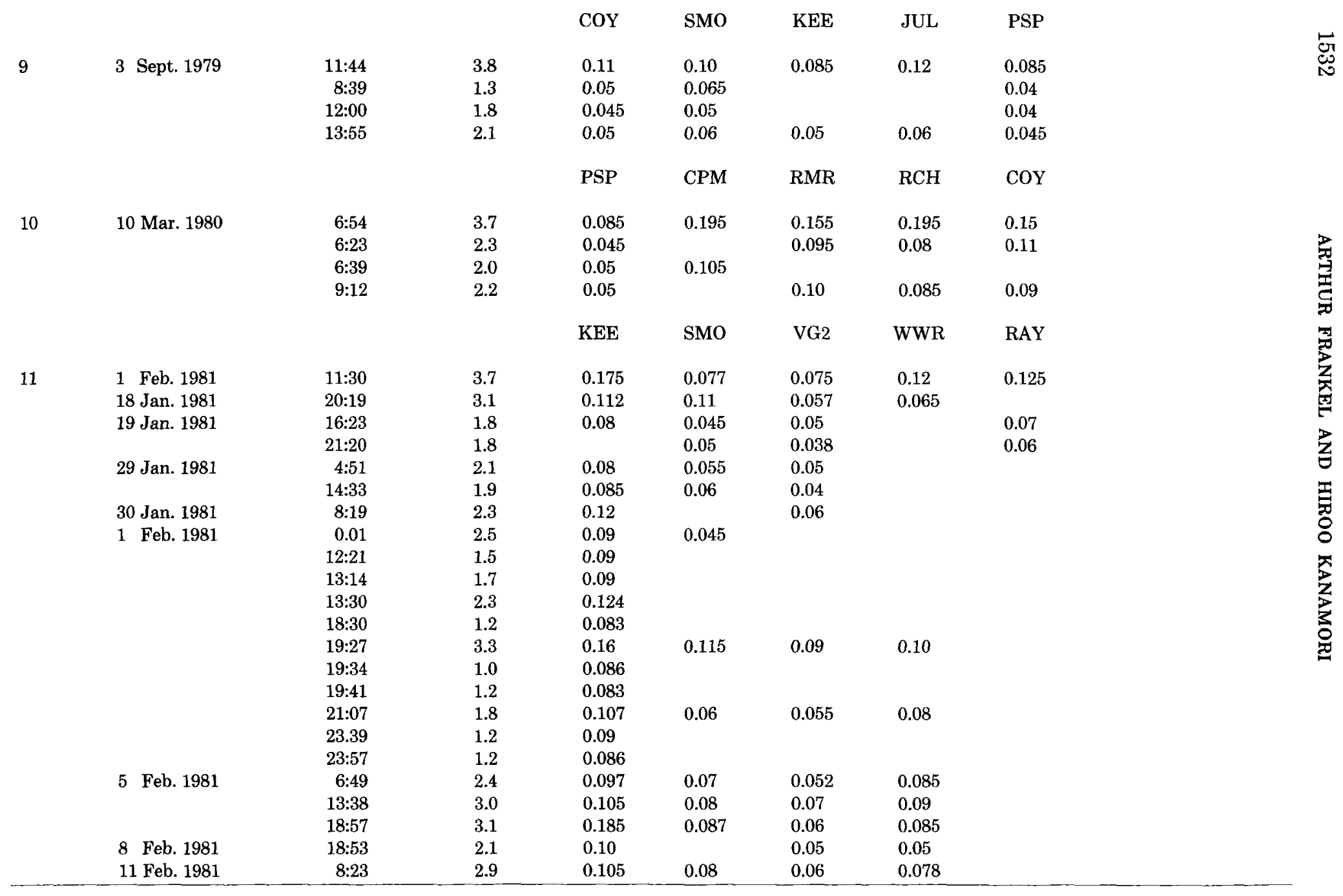


problem, because analog tape records for these earthquakes were not saved. The pulse widths for these events were measured from the digital seismograms that were processed to remove the effects of the antialiasing filters. The digital seismograms were transformed to the frequency domain, divided by the response of the filter, and transformed back to the time domain. The accuracy of this method was tested by using stations which were digitally recorded both with and without the antialiasing filter. A comparison of seismograms obtained by deconvolving the filtered records with the original, unfiltered seismograms showed that our procedure accurately reproduced the $\tau_{1 / 2}$ of the original waveforms.

Two of the stations utilized in this study are CIT stations with a different response than the standard USGS installation (see Figure 2). This response produces a significant broadening of the pulse width. These stations are noted in Table 2. As we will show in a later section, the pulse broadening caused by the instruments at these two stations is effectively removed by the procedure we use to determine source duration.

\section{Pulse Width as a Function of Magnitude}

Figure 3 shows $\tau_{1 / 2}$ as a function of magnitude for four earthquake sequences. These values of pulse width were read directly from the unprocessed digital playbacks for earthquakes associated with main shocks 1,2, and 3. Although the digital system samples every $0.02 \mathrm{sec}$, we linearly interpolated between data points to estimate $\tau_{1 / 2}$ to within $0.005 \mathrm{sec}$. For the events accompanying main shock $11, \tau_{1 / 2}$ was measured directly from playbacks of the analog tapes.

It is clear from Figure 3 that, in most cases, $\tau_{1 / 2}$ decreases to a minimum value that remains constant as the magnitude decreases. This effect is observed for the aftershocks of event 1 recorded at RMR and PSP, for the foreshocks and aftershocks of event 2 at SIL and RAY, for the aftershock of event 3 at SIL and RAY, and for the swarm events that occurred with event 11 at station KEE. This leveling off of $\tau_{1 / 2}$ with magnitude is not apparent for the swarm events accompanying event 11 for the two other stations used (SMO and VG2). However, these stations were noisier than KEE so that pulse widths of events less than magnitude 1.7 could not be measured for these stations. Constancy of pulse width as a function of magnitude has also been reported by O'Neill and Healy (1973) for earthquakes less than magnitude 2.0 in central California.

The threshold magnitude where $\tau_{1 / 2}$ levels off varies from 2.8 to about 1.8 and does not appear to be a function of distance. Stations at similar distances from a given sequence often display different values of $\tau_{1 / 2}$. It should be stressed that the minimum pulse width that is observed cannot be caused by the instrument response. Figure 3 also provides a check on the reliability of the zero crossings from clipped records. The magnitude where clipping occurs is shown by an arrow for each station. It is apparent that $\tau_{1 / 2}$ remains nearly unchanged between unclipped and clipped seismograms in many cases. Thus, the clipping does not alter the value of $\tau_{1 / 2}$ for these events.

As an example, the waveforms of two events differing in magnitude but having about the same $\tau_{1 / 2}$ 's are depicted in Figure 4. These two foreshocks to event 2 exhibit very similar waveforms despite their difference in amplitude of a factor of about seven. The relative seismic moments of events with similar values of $\tau_{1 / 2}$ is equal to their relative amplitudes. Thus, the difference in the log of the seismic moments for events shown in Figures 3 and 4 with similar pulse widths is equal to 
TABLE 2

Station and Event Data

\begin{tabular}{|c|c|c|c|c|c|c|}
\hline Event No. & Depth (km) & Station & Delta $(\mathrm{km})$ & Azımuth (deg) & $\begin{array}{c}\text { Minımum } \\
\left(\left(T^{1 / 2}\right)\right.\end{array}$ & $\begin{array}{c}\text { Corrected } \\
\left(\tau^{1 / 2}\right)\end{array}$ \\
\hline \multirow[t]{6}{*}{1} & $5.0^{*}$ & PSP & 20.4 & 170 & 0.05 & 0.04 \\
\hline & & RAY & 22.0 & 288 & 0.07 & 0.06 \\
\hline & & RMR & 26.4 & 2 & 0.05 & 0.06 \\
\hline & & INS & 36.4 & 97 & 0.085 & 0.035 \\
\hline & & MDA & 38.9 & 260 & 0.06 & 0.065 \\
\hline & & $\mathrm{PEC} \dagger$ & 54.0 & 260 & 0.10 & 0.05 \\
\hline \multirow[t]{3}{*}{2} & $0.3^{*}$ & SIL & 11.6 & 293 & 0.08 & 0.08 \\
\hline & & RAY & 31.7 & 196 & 0.07 & 0.08 \\
\hline & & $\mathrm{CKC}$ & 46.5 & 246 & 0.065 & 0.075 \\
\hline \multirow[t]{7}{*}{3} & 76 & SIL & 27.9 & 298 & 0.065 & 0.135 \\
\hline & & RAY & 31.3 & 227 & 0.06 & 0.08 \\
\hline & & INS & 46.8 & 133 & 0.065 & 0.095 \\
\hline & & TPC $\dagger$ & 49.2 & 106 & 0.125 & 0.095 \\
\hline & & RDM & 60.5 & 289 & 0.065 & 0.125 \\
\hline & & SDW & 63.4 & 312 & 0.06 & 0.15 \\
\hline & & KEE & 65.8 & 187 & 0.06 & 0.05 \\
\hline \multirow[t]{3}{*}{4} & 1.6 & MOV & 30.5 & 1 & 0.07 & 0.06 \\
\hline & & RMR & 37.4 & 350 & 0.11 & 0.07 \\
\hline & & SMO & 38.5 & 174 & 0.04 & 0.05 \\
\hline \multirow[t]{3}{*}{5} & 4.4 & CKC & 25.0 & 94 & 0.065 & 0.095 \\
\hline & & SME & 37.0 & 167 & 0.05 & 0.07 \\
\hline & & PEM & 39.4 & 272 & 0.105 & 0.105 \\
\hline \multirow[t]{5}{*}{6} & 17.6 & SMO & 5.9 & 38 & 0.035 & 0.035 \\
\hline & & KEE & 21.4 & 319 & 0.05 & 0.03 \\
\hline & & COY & 22.8 & 129 & 0.06 & 0.025 \\
\hline & & PSP & 33.6 & 352 & 0.055 & 0.025 \\
\hline & & RAY & 66.6 & 335 & 0.095 & 0.025 \\
\hline
\end{tabular}




\begin{tabular}{|c|c|c|c|c|c|c|}
\hline \multirow[t]{5}{*}{7} & 16.6 & SMO & 5.6 & 52 & 0.035 & 0.055 \\
\hline & & KEE & 19.9 & 318 & 0.05 & 0.09 \\
\hline & & $\mathrm{COY}$ & 242 & 130 & 0.06 & 0.055 \\
\hline & & PSP & 32.3 & 353 & 0055 & 0.04 \\
\hline & & RAY & 65.2 & 335 & 0.095 & 0.055 \\
\hline \multirow[t]{4}{*}{8} & 7.2 & BLU & 2.3 & 160 & 0.05 & 0035 \\
\hline & & LJB & 212 & 334 & 0.045 & 0.045 \\
\hline & & $\mathrm{ADL}$ & 33.8 & 63 & 005 & 0045 \\
\hline & & $\mathrm{RDM}$ & 51.6 & 92 & 0.09 & 0.04 \\
\hline \multirow[t]{5}{*}{9} & $5.0^{*}$ & COY & 6.1 & 113 & 0.045 & 0.065 \\
\hline & & SMO & 19.1 & 334 & 0.05 & 0.05 \\
\hline & & $\mathrm{KEE}$ & 33.7 & 317 & 0.05 & 0.035 \\
\hline & & JUL & 43.3 & 212 & 0.04 & 0.06 \\
\hline & & PSP & 48.6 & 340 & 004 & 0.045 \\
\hline \multirow[t]{5}{*}{10} & $5.0^{*}$ & PSP & 27.2 & 247 & 0045 & 0.04 \\
\hline & & CPM & 30.2 & 15 & 0105 & 0.09 \\
\hline & & RMR & 45.0 & 323 & 0.095 & 0.06 \\
\hline & & $\mathrm{RCH}$ & 46.7 & 352 & 0.08 & 0.115 \\
\hline & & $\mathrm{COY}$ & 58.9 & 183 & 0.09 & 0.06 \\
\hline \multirow[t]{5}{*}{11} & 2.6 & KEE & 18.2 & 36 & 0.08 & 0.095 \\
\hline & & SMO & 28.7 & 83 & 0.045 & 0032 \\
\hline & & $\mathrm{VG} 2$ & 36.5 & 354 & 0.038 & 0.037 \\
\hline & & WWR & 55.0 & 11 & 0.05 & 0.07 \\
\hline & & RAY & 59.1 & 356 & 0.06 & 0.065 \\
\hline
\end{tabular}

* Depth poorly constrained.

+ CIT station. 


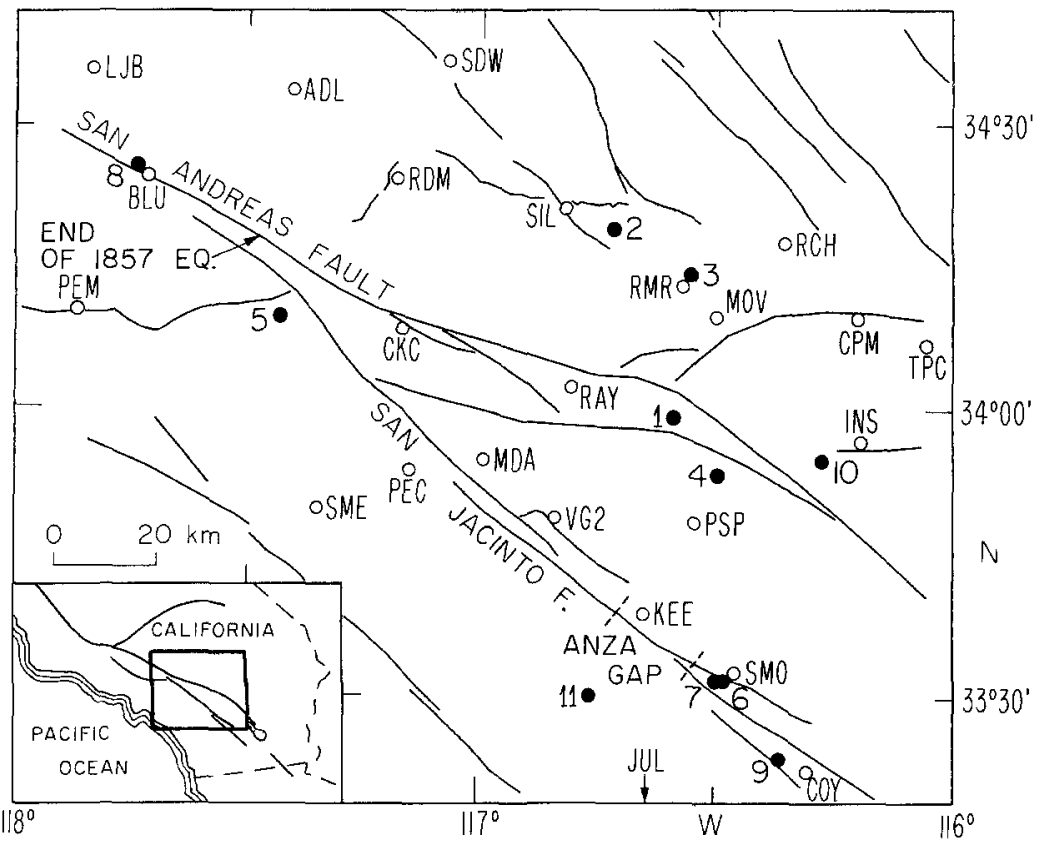

Fig 1. Map of southern Californıa showing main shocks studied (with identification numbers), stations used, and major faults Approximate location of the southern end of the rupture zone of the great 1857 earthquake and the position of the Anza seismic gap (Thatcher et al, 1975) are also indicated.
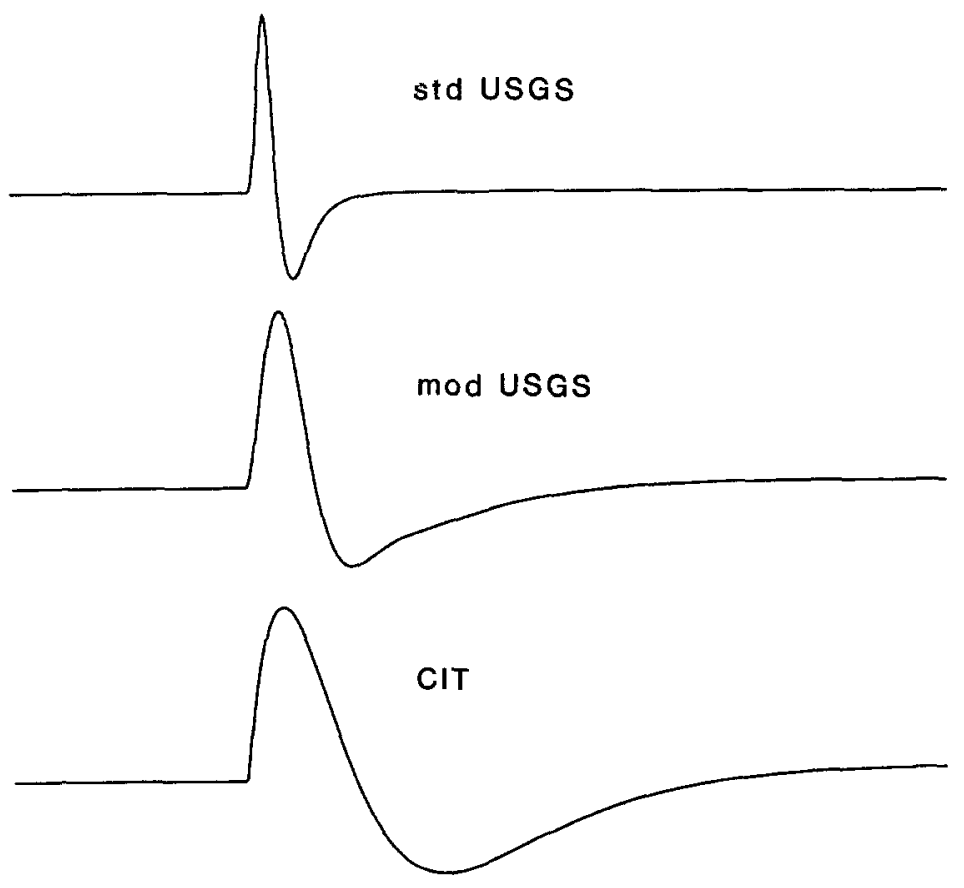

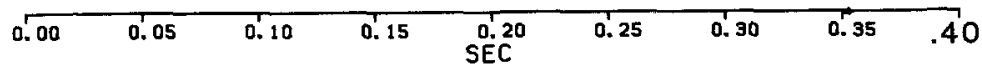

FIG. 2 Impulse responses of varıous instrumentation used in this study, derived from characteristıcs reported in Archambeau (1979) - standard USGS configuration (top), modified USGS system with antialiasing filter (middle), and CIT system (bottom). 

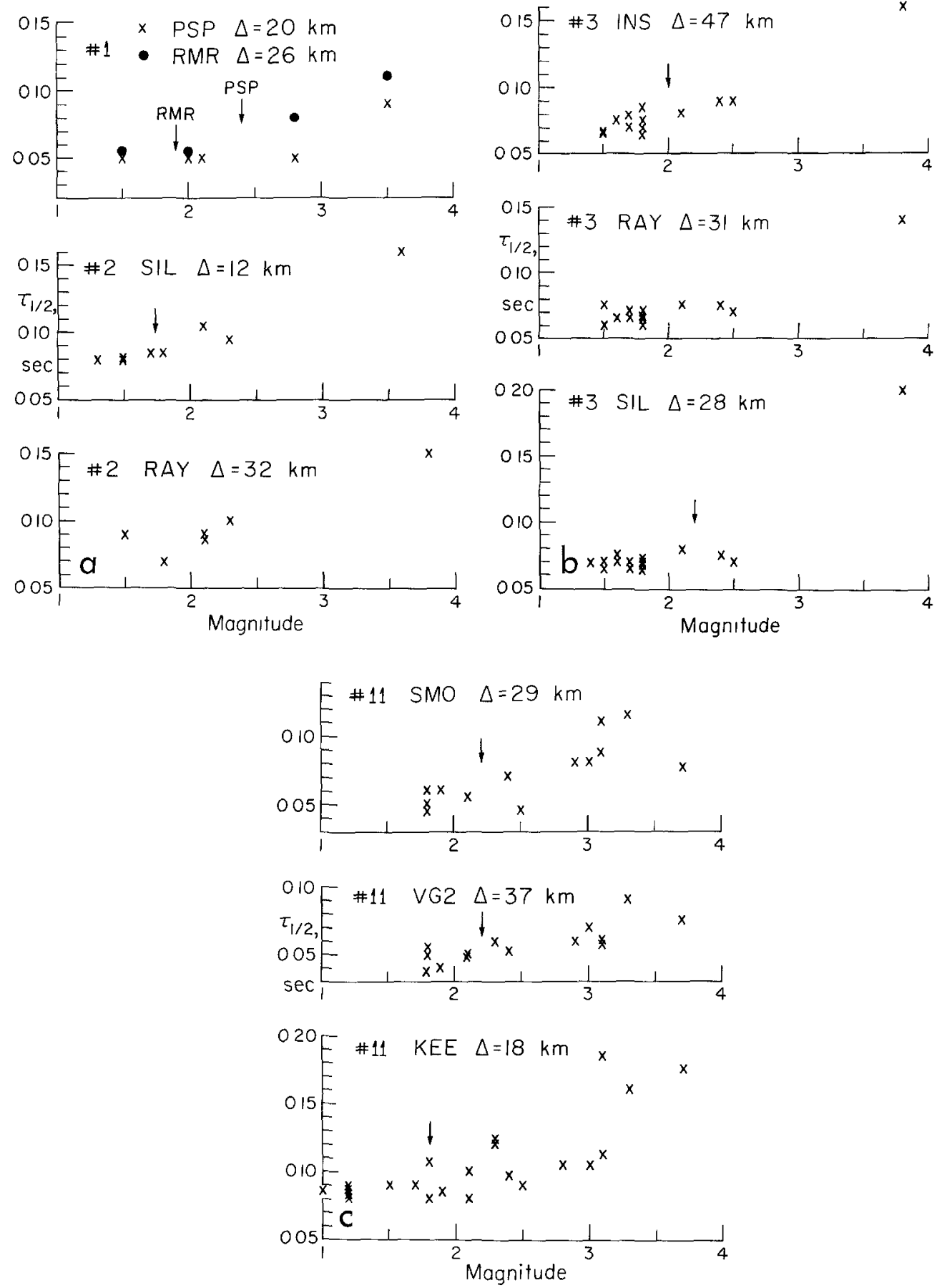

FIG. 3. Initual pulse width ( $\left.\tau_{1 / 2}\right)$ plotted against magnitude for (a) main shocks 1 and 2 and their foreshocks and aftershocks; (b) main shock 3 and its aftershocks, and (c) swarm events associated with event 11 The station and epicentral distance are shown on each graph. Arrows denote the approximate magnitude where clipping occurs for that partıcular source-receiver pair Note the presence of a minımum value of $\tau_{1 / 2}$ at several stations for earthquakes below about magnitude 22

the difference in their magnitudes. Figure 4 illustrates that the pulse width of these foreshocks remains the same despite a factor of seven difference in seismic moment.

Many studies have found that the corner frequencies of microearthquakes remain constant with decreasing seismic moment. This is the frequency domain equivalent 
of the constancy of $\tau_{1 / 2}$ with moment noted here. Bakun et al. (1976), Frankel (1982), and Archuleta et al. (1982), among others, report that corner frequencies of events with seismic moments less than about $10^{21}$ dyne-cm $(M \approx 3.0)$ remain constant as seismic moment decreases. This finding contrasts with the scaling behavior of larger events, where the corner frequency increases with decreasing moment in a manner that preserves a constant stress drop (see Thatcher and Hanks, 1973; Archuleta et al., 1982). Many authors attribute the uniformity of corner frequency for small events to a property of the source such that the source size of these events remains constant with decreasing moment.

The interpretation that forms the basis of this paper is that the corner frequencies and pulse widths of these small events $(M<2.2)$ are controlled entirely by the propagation path. In this view, the source duration of these small earthquakes is

\section{2/5/78 RAY $32 \mathrm{~km}$}
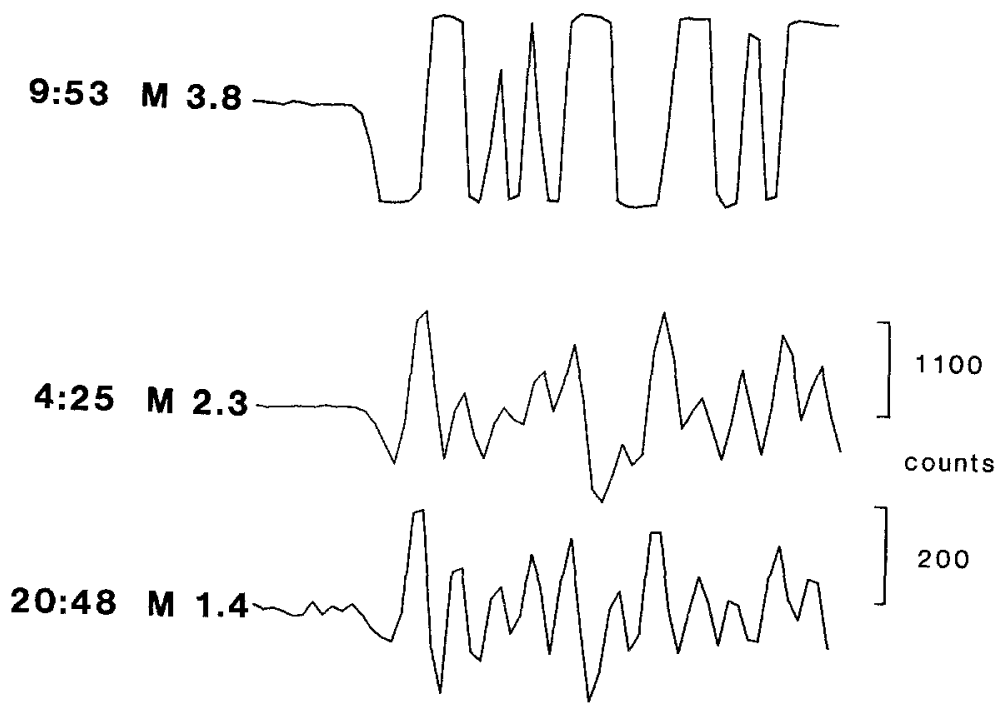

2 SEC

FIG. 4. Waveforms of event $2\left(M_{L}=3.8\right)$ and two of its foreshocks recorded at RAY $(\Delta=32 \mathrm{~km})$ Note the equivalence of $\tau_{1 / 2}$ for the two foreshocks despite their difference in amplitudes (and, therefore, seismic moments).

essentially a delta function compared to the pulse broadening produced by the path. As the moment of the event becomes smaller, the waveform remains the same but decreases in amplitude. The waveform on the small event represents the impulse response of the path for an earthquake with that particular radiation pattern.

Two observations point to propagation effects as the cause for this constancy of pulse width observed for small earthquakes. The minimum value of $\tau_{1 / 2}$ for a given sequence often varies from station to station (see Table 2), even for stations at comparable distances. It can be argued that azimuthally dependent values of $\tau_{1 / 2}$ can be produced by several models of the earthquake source and might be responsible for the apparent site-dependence of the minimum $\tau_{1 / 2}$. However, stations whose azimuths differ by less than $30^{\circ}$ often display different values of pulse width.

The minimum pulse widths illustrated in Figure 3 cannot be accounted for by the values of average, whole path attenuation commonly reported for the California region (see, e.g., Singh et al., 1982). To quantify the effects of intrinsic attenuation on $\tau_{1 / 2}$, we convolved a Futterman attenuation operator (see Carpenter, 1966) with 
the instrument response. Using a reasonable value for $Q_{P}$ of 250 and a travel time corresponding to a distance of $30 \mathrm{~km}$, the $\tau_{1 / 2}$ of the resulting waveform is only $0.029 \mathrm{sec}$. This is much less than the minimum values of $\tau_{1 / 2}$ shown in Figure 3, which range from 0.05 to $0.08 \mathrm{sec}$ for stations 18 to $31 \mathrm{~km}$ distant from the earthquakes. The minimum pulse widths may be caused by severe apparent attenuation at shallow depths (see Frankel, 1982), which would not be detected by studies of attenuation that primarily sample depths greater than a few kilometers. Table 2 shows that certain stations display different values of minimum $\tau_{1 / 2}$ for different propagation paths. $\tau_{1 / 2}$ does not systematically increase for a given earthquake as the distance to the station increases. This implies that either the site response has a large effect on the pulse width or that propagation paths of similar distance produce different amounts of pulse broadening.

\section{Determination of Source Parameters}

Using the waveforms of small events as empirical Green's functions, we can estimate the rupture durations of main shocks greater than magnitude 3.5 . The waveform of the main shock $\left(A_{\text {main }}(t)\right)$ is formed by the convolution of the Green's function $(G(t))$ with the source-time function $\left(S_{\text {main }}(t)\right)$ and the instrument response $(I(t))$, so that

$$
A_{\text {main }}(t)=S_{\text {main }}(t)^{*} G(t)^{*} I(t)
$$

Since the source-time function of a small, adjacent aftershock or foreshock is essentially a delta function, its waveform $\left(A_{\text {after }}(t)\right)$ represents the convolution of the Green's function with the instrument response

$$
A_{\text {after }}(t)=G(t)^{*} I(t)
$$

yielding from (1)

$$
A_{\text {main }}(t)=S_{\text {main }}(t)^{*} A_{\text {after }}(t)
$$

Thus, to determine the duration of the source-time function of this main shock, we have to deconvolve the aftershock waveform from the main shock waveform. However, the clipping of the main shock waveform precludes this deconvolution.

A simple procedure can be invoked to approximate this deconvolution of the initial pulse of the aftershock waveform from that of the main shock. Figure 5 depicts the waveforms of a main shock (event 3 ) and one of its aftersocks. This figure also contains the waveforms that result when the aftershock waveform is convolved with a source-time function which has a triangular shape and varying durations. It is apparent that the $\tau_{1 / 2}$ of the resultant waveform is approximately equal to the sum of the $\tau_{1 / 2}$ of the aftershock waveform plus the half-duration of the source-time function. This summation is a general result for the convolution of two relatively symmetrical pulses. Therefore, we can essentially deconvolve the empirical Green's function from the clipped record of the main shock by subtracting the $\tau_{1 / 2}$ of the Green's function $\left(\tau_{1 / 2}^{\text {after }}\right)$ from the $\tau_{1 / 2}$ of the main shock $\left(\tau_{1 / 2}^{\text {main }}\right)$

$$
\tau_{1 / 2}^{\text {source }} \approx \tau_{1 / 2}^{\text {main }}-\tau_{1 / 2}^{\text {after }} .
$$

The result is an approximate estimate of the half pulse width $\left(\tau_{1 / 2}^{\text {source }}\right)$ of the source- 
time function required to convert the Green's function pulse width into the main shock's pulse width. A simple triangular shape of the time function is used in this example, but any symmetrical, unipolar pulse would yield similar results. It is important to note that since the main shock and aftershock waveforms are recorded by the same instrument, "deconvolving" one waveform from the other by this subtraction effectively cancels the slight effect of the instrument on $\tau_{1 / 2}$.

If aftershock waveforms can indeed be thought of as empirical Green's functions,

\section{$4 / 29 / 78$ SIL $28 \mathrm{~km}$}

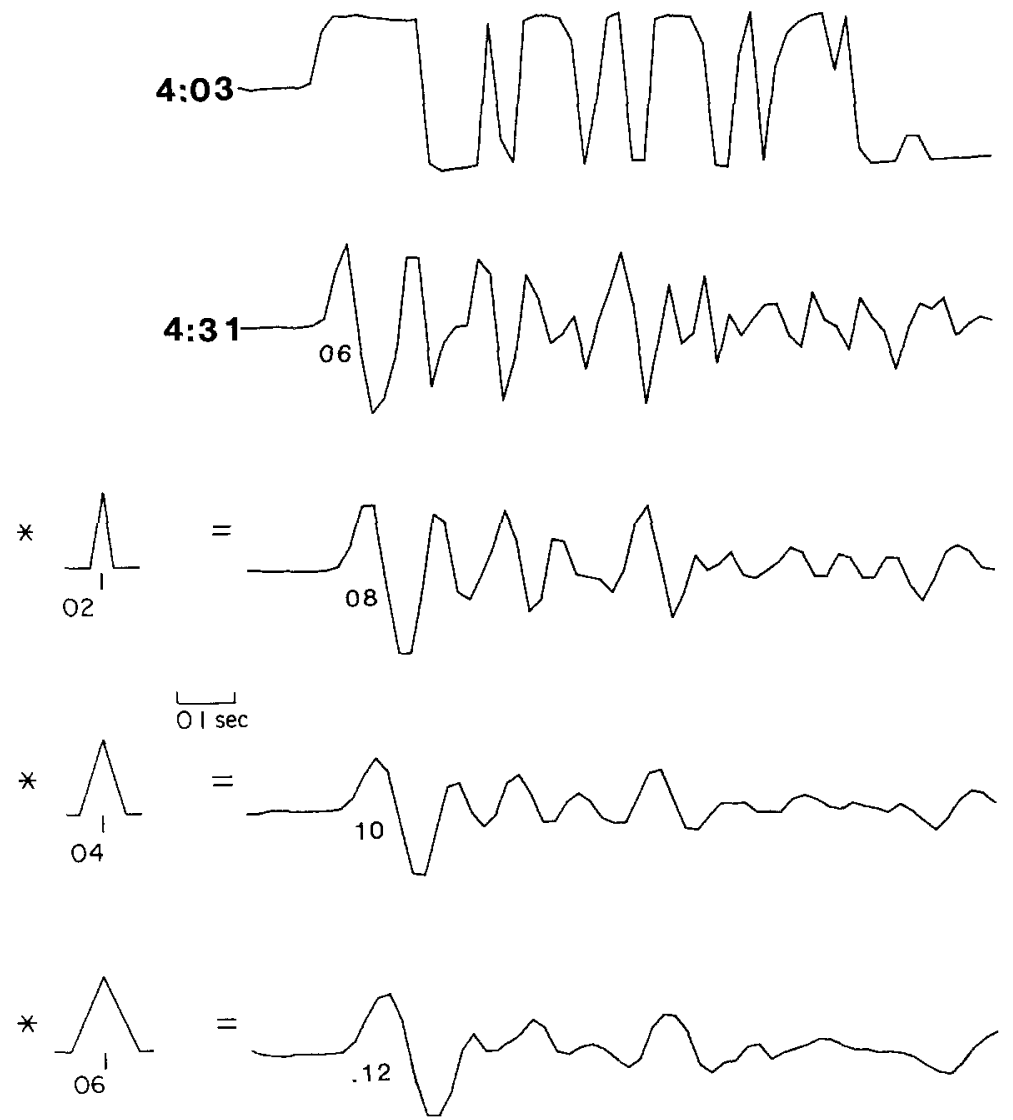

FIG. 5. Waveforms of event $3\left(4: 03\right.$ UTC, $\left.M_{L}=3.8\right)$ and one of its aftershocks $(4 \cdot 31$ UTC) recorded at SIL. The waveforms shown below the $4: 31$ event represent the convolution of the $4: 31$ waveform with the source-time functions indicated to the left Note that the $\tau_{1 / 2}$ 's of the convolved waveforms are approxımately equal to the sum of the $\tau_{1 / 2}$ of the original waveform and the half duration of the source function.

equation (4) implies that, for a particular source region, stations with relatively large values of $\tau_{1 / 2}$ for the main shock will also have relatively large $\tau_{1 / 2}$ 's for the aftershocks, compared to other stations. We tested this implication by calculating $\tau_{1 / 2}$ residuals for nine of the main shock-aftershock sequences studied. Two of the main shocks had azimuthally dependent values of $\tau_{1 / 2}$ that were consistent with unilateral rupture propagation and, therefore, were not included in this residual analysis. The $\tau_{1 / 2}$ residual for each station-event pair was determined by subtracting the $\tau_{1 / 2}$ observed at that station for a given event from the $\tau_{1 / 2}$ for that event averaged over all of the stations that were usable. Thus, a station exhibiting a broad 
pulse width relative to other stations that recorded the event will have a positive residual.

Figure 6 shows a plot of the $\tau_{1 / 2}$ residuals for the aftershocks with the minimum values of $\tau_{1 / 2}$ graphed as a function of the $\tau_{1 / 2}$ residuals for the corresponding main shocks. This figure clearly indicates that the relative pulse widths of main shocks and aftershocks are correlated for a particular source-station pair. This observation provides further support for our interpretation of the waveforms of small earthquakes as empirical Green's functions.

The $\tau_{1 / 2}$ of the source-time function derived from equation (4) is converted to an estimate of source radius using a model of an earthquake source specified by Sato and Hirasawa (1973). In this model, the earthquake nucleates at a point, grows

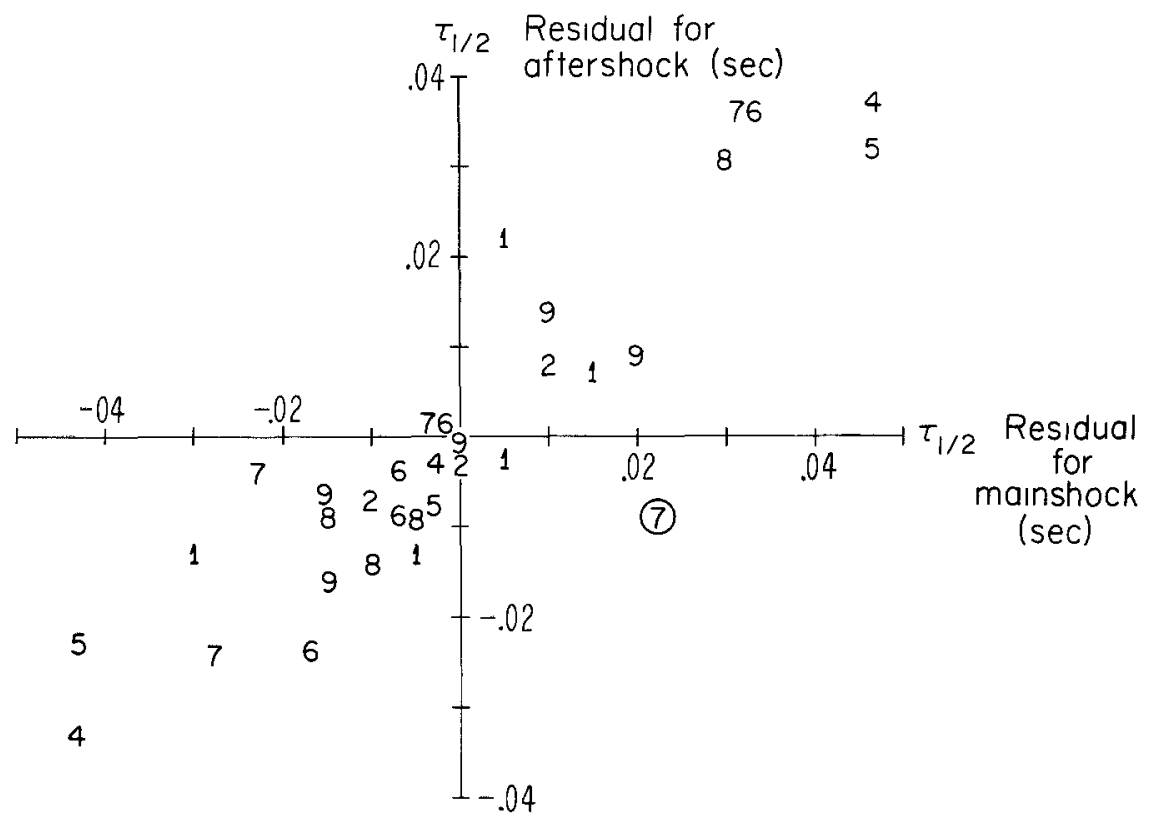

FIG. 6 The $\tau_{1 / 2}$ resıduals observed at a particular station for each main shock plotted against the $\tau_{1 / 2}$ residual of its aftershock with the smallest pulse width recorded at that station The correlation of these residuals indicates that stations with relatıvely large pulse widths for a given main shock also display relatively large pulse widths for its aftershocks. The residuals are plotted by numbers corresponding to the event identification numbers

outward as a circular rupture with a constant rupture velocity $v$, and stops instantaneously. The fault radius $r$ is then related to $\tau_{1 / 2}$ by

$$
r=\frac{\tau_{1 / 2} v}{1-\frac{v}{c} \sin \theta},
$$

as specified by Boatwright (1980). Here, $c$ is the wave velocity and $\theta$ denotes the angle between the normal to the fault plane and the outgoing seismic ray. We assume that all of the main shocks studied had a rupture velocity of 0.9 times the shear wave velocity. The $P$-wave velocity is taken to be $6.5 \mathrm{~km} / \mathrm{sec}$ and the value of $\theta$ is set at $45^{\circ}$ for all the calculations.

The seismic moments of these main shocks were determined from their local magnitudes derived from the maximum $S$-wave amplitudes on Wood-Anderson 
records. These maximum spectral amplitudes determined from these records should be directly proportional to the amplitude of the flat, long-period portion of the displacement spectrum because the instrument has a flat displacement response above $1.25 \mathrm{~Hz}$ and the apparent $S$-wave corner frequencies for these events are above $2 \mathrm{~Hz}$. If the spectra of the Wood-Anderson records at regional distances $(>200 \mathrm{~km}$ ) are bandlimited at high frequencies by seismic attenuation, the maximum time domain amplitude on the records is directly proportional to the seismic moment. Therefore, we use the relationship of Archuleta et al. (1982) for moment $\left(M_{0}\right)$ as a function of local magnitude $\left(M_{L}\right)$ that was established for earthquakes near Mammoth Lakes, California,

$$
\log M_{0}=1.05 M_{L}+17.76 \text {. }
$$

The exact form of the moment-magnitude relationship is not crucial to the results of this paper because we are studying events in a very limited magnitude range. Once the average fault radius $r$ and seismic moment are determined for each event, the stress drop $\Delta \sigma$ is calculated from Brune's (1970) formula for a circular fault

$$
\Delta \sigma=\frac{7}{16} \frac{M_{0}}{r^{3}} .
$$

It should be emphasized that the absolute values of the stress drops reported here are highly dependent on the proportionality one uses between $\tau_{1 / 2}$ and the source radius [equation (5)]. This proportionality is very sensitive to the rupture velocity. Furthermore, other source models yield different proportionalities. However, our major purpose is to detect relative differences in rupture duration and stress drop. These relative variations are not affected by the choice of source models, unless different models are required to describe different earthquakes.

\section{EFFEcts of UNILATERAL RUPTURE}

The preceding method for determining rupture dimension is not valid for a unilaterally propagating fault. Evidence for unilateral rupture growth is demonstrated in both the aftershock locations and the azimuthal variation of $\tau_{1 / 2}$ measured for event 3 in the southern Mojave. The top portion of Figure 7 depicts a map with the locations of the main shock and the aftershocks that occurred within $24 \mathrm{hr}$. These hypocenters were derived from master event relocations. Almost all of the aftershocks are situated to the south of the main shock, indicating that the main shock ruptured unilaterally to the south from its hypocenter.

A plot of path-corrected values of $\tau_{1 / 2}$ as a function of azimuth is also shown in Figure 7. $\tau_{1 / 2}$ reaches a minimum at an azimuth of about $180^{\circ}$, due south of the epicenter. This pattern of $\tau_{1 / 2}$ with azimuth is consistent with an earthquake rupturing unilaterally to the south. For this analysis, we assumed the rupture propagated horizontally on a vertical strike-slip fault striking north-south. This focal mechanism is consistent with first motion data of this shock obtained from the local network. Because of the shallow depth of the source $(7 \mathrm{~km})$ and the distance to the stations ( 28 to $66 \mathrm{~km}$ ), the rays are essentially taking off horizontally from the source. In Figure 6 , we show the curve calculated for $\tau_{1 / 2}$ for such a source, where $\tau_{1 / 2}$ is taken to be the time between the $P$ wave emitted from the point of nucleation and the $P$ wave produced at the southern end of the fault when the 
rupture reaches that end (see Ben-Menahem, 1962; Boatwright, 1980), so that

$$
\tau_{1 / 2}=\left(1-\frac{v}{c} \cos \varphi\right) \frac{a}{v} .
$$

In this formula, $\varphi$ represents the azimuth of the outgoing ray measured with respect to the direction of rupture propagation and $a$ denotes the rupture length. The curve shown is the best fit to the data and yields a rupture velocity of $0.9 v_{s}$ and a fault
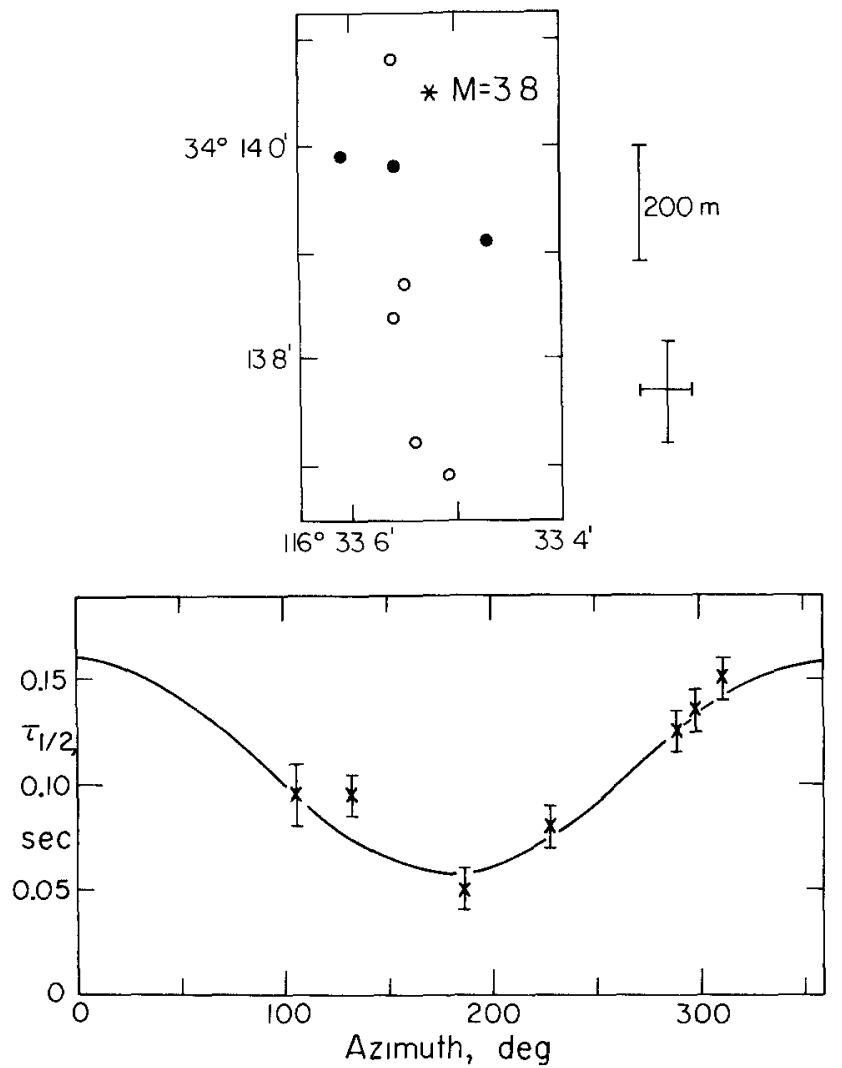

FIG. 7 (Top) Master event relocations of event 3 and its aftershocks. Filled circles represent aftershocks withın $1 \mathrm{hr}$ of the main shock, and open circles are aftershocks within 1 day. Error bars of the relative locations are shown to the right (Bottom) Path-corrected values of $\tau_{1 / 2}$ for the main shock plotted against azımuth from the epıcenter to the station. Curve indicates predicted values of $\tau_{1 / 2}$ derived for a rupture propagating unilaterally to the south (see text).

length of $360 \mathrm{~m}$. The curve derived from this procedure explains the azimuthal differences in $\tau_{1 / 2}$, although the constraint on the rupture velocity is weak. The calculated fault length falls between the length of the aftershock zone defined by aftershocks within $1 \mathrm{hr}$ of the main shock $(250 \mathrm{~m})$ and that produced by aftershocks within 1 day ( $650 \mathrm{~m}$, see Figure 7 ).

The value of rupture length derived by this method differs from the fault radius that would be calculated from equation (5) using the average value of $\tau_{1 / 2}$. We determined the fault radii and stress drops of all the main shocks studied from the average $\tau_{1 / 2}$ and equations (5) and (7). We recognize that the assumption of circular 
faulting is probably incorrect for the events with unilateral rupture. However, our approach was chosen so that the calculated stress drops would be a relative measure of the ratio between the seismic moment and the rupture duration. In this sense, the stress drops estimated for the earthquakes with unilateral rupture can be compared with the others.

The important finding conveyed in Figure 7 is that two independent pieces of evidence, aftershock locations, and variations in pulse widths, confirm that event 3 ruptured unilaterally to the south. This observation gives us confidence that $\tau_{1 / 2}$ is indeed a measure of the apparent rupture duration of an earthquake.

\section{Results: Rupture Durations and Stress Drops}

The average values of $\tau_{1 / 2}$, both original and corrected for path effects by subtracting the minimum $\tau_{1 / 2}$ of the aftershocks, are graphed in Figure 8 for 10 of

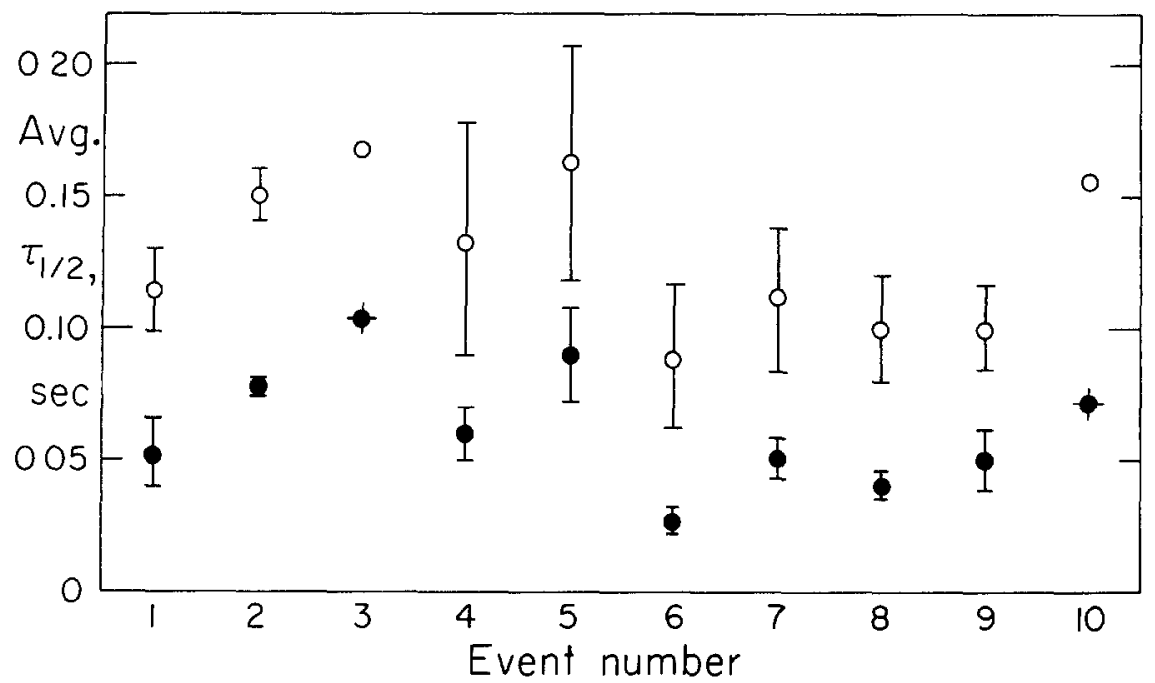

FIG 8 Average values of $\tau_{1 / 2}$ plotted as a function of event number Open circles represent original values measured from the seismograms, and filled circles denote values of $\tau_{1 / 2}$ corrected using aftershock pulse widths Circles with crosses are events with azimuthal variations in $\tau_{1 / 2}$ indicative of unilateral rupture propagation.

the main shocks studied (see also Tables 2 and 3). Event 11 yielded inconsistent readings at stations at similar azimuths and will be discussed later. The points plotted in Figure 8 represent the averages of $\tau_{1 / 2}$ from 3 to 7 stations for each event. The error bars denote one standard deviation. For events 6 and 7 , the readings from station KEE were not included in the averages and will be noted later. The pathcorrected values of $\tau_{1 / 2}$ are about one-half of the original $\tau_{1 / 2}$ 's measured from the seismograms. Two of the main shocks (events 3 and 10) appeared to have an azimuthal dependence of $\tau_{1 / 2}$ indicative of unilateral rupture and are shown with different symbols in Figure 8.

The standard deviations in $\tau_{1 / 2}$ for each sequence are generally much lower for the path-corrected values than the original pulse widths. This demonstrates that we can account for a large portion of the scatter in pulse widths for a given event by variations in the path effects. The corrected values of $\tau_{1 / 2}$ track the uncorrected values very well. For example, event 6 has the shortest uncorrected value of average $\tau_{1 / 2}$ and also the smallest corrected average. Thus, we are not introducing a bias between each event by using the empirically derived path corrections. 
Figure 9 shows the average values of $\tau_{1 / 2}$, both original and path-corrected, plotted as a function of the local magnitude of the events. The lines of constant stress drop depicted in Figure 9 were derived from the relationship between $M_{L}$ and seismic moment given by equation (6). This figure illustrates that the differences in pulse

TABLE 3

\begin{tabular}{|c|c|c|c|c|}
\hline $\begin{array}{l}\text { Event } \\
\text { No }\end{array}$ & $\begin{array}{c}\text { Moment } \\
\left(10^{21} \text { dyne-cm) }\right.\end{array}$ & $\begin{array}{c}\text { Average } \\
\text { Corrected } \\
\tau_{1 / 2}(\mathrm{sec})\end{array}$ & $\begin{array}{l}\text { Raduus } \\
\text { (m) }\end{array}$ & $\begin{array}{l}\text { Stress } \\
\text { Drop } \\
\text { (bars) }\end{array}$ \\
\hline 1 & 2.7 & 0052 & 260 & 66 \\
\hline 2 & 56 & 0078 & 390 & 40 \\
\hline 3 & 5.6 & 0.104 & 530 & 17 \\
\hline 4 & 4.4 & 0.060 & 300 & 69 \\
\hline 5 & 7.2 & 0090 & 460 & 33 \\
\hline 6 & 56 & 0.028 & 140 & 860 \\
\hline 7 & 3.5 & 0.051 & 260 & 88 \\
\hline 8 & 7.2 & 0041 & 210 & 350 \\
\hline 9 & 56 & 0051 & 260 & 140 \\
\hline 10 & 4.4 & 0073 & 370 & 38 \\
\hline
\end{tabular}

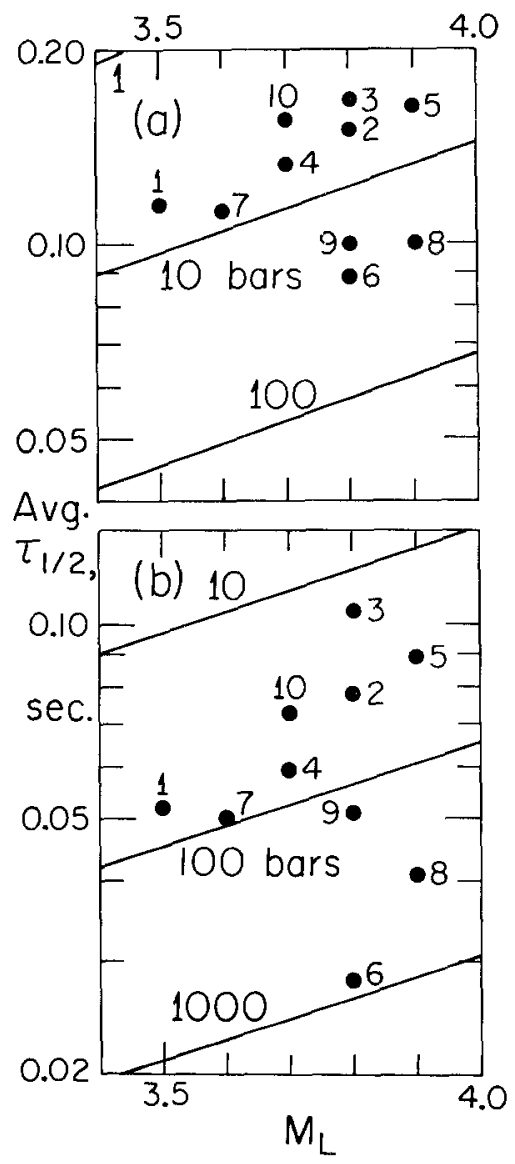

FIG. 9 (a) Original and (b) path-corrected values of $\tau_{1 / 2}$ plotted against local magnitude for the 10 main shocks studied Note that $\tau_{1 / 2} 1$ s plotted on a logarithmic axis Slanted lines denote lines of constant stress drop. Event numbers are given beside symbols. Diagonal lines represent lines of constant stress drop. 
width occur in events of similar magnitudes. The stress drops calculated from the path-corrected $\tau_{1 / 2}$ 's are about 10 times higher than those determined from the original $\tau_{1 / 2}$ 's measured from the seismograms. Events 6 and 8 appear to plot below the field of the other events in both graphs, indicating that they had relatively high stress drops.

The stress drops calculated for these earthquakes are graphed in Figure 10 and displayed in map view in Figure 11 (see also Table 3). Seven events had stress drops estimated between 30 and 140 bars. The shock with the shortest value of $\tau_{1 / 2}$, event 6 , also had a significantly higher stress drop ( 860 bars) than the other events studied. The stress drops do not display a dependence on moment for this limited range of magnitude. There is no simple correlation observed between stress drop

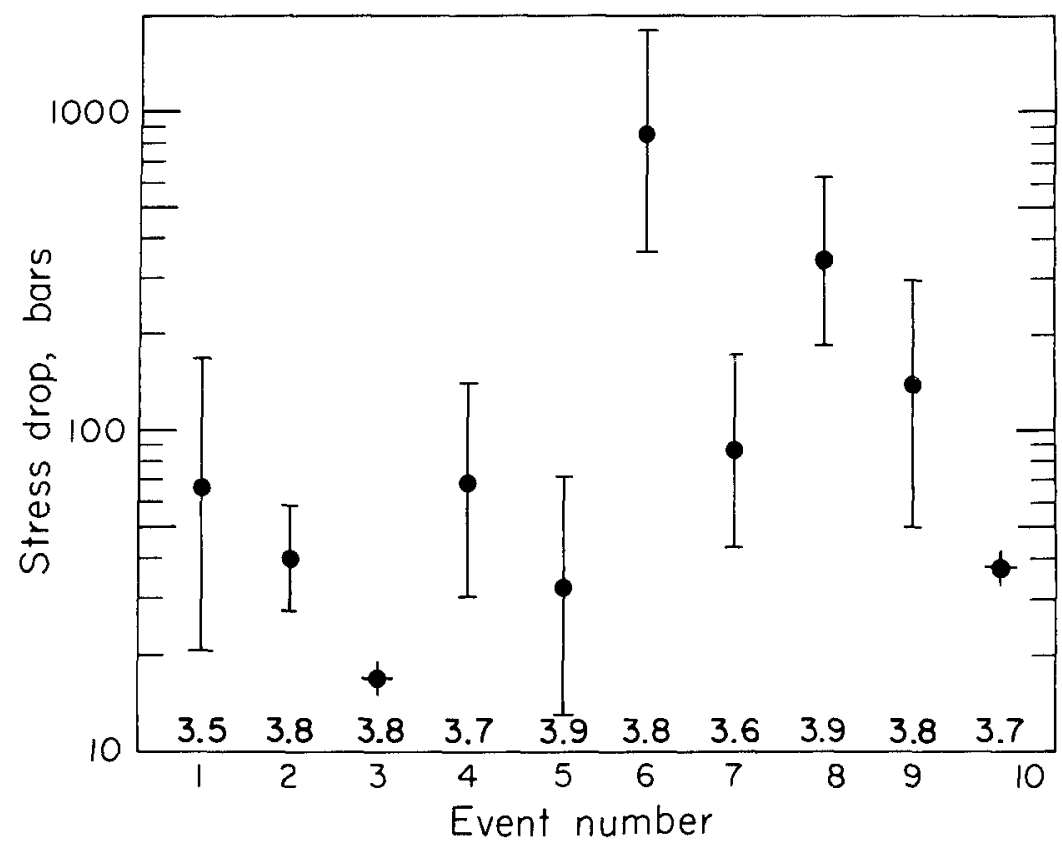

Fig 10. Statıc stress drop plotted against event number. The local magnitude of each event is shown above its ID number Curcles with crosses again represent earthquakes with inferred unlateral rupture Note the relatively high stress drop of event 6 .

and source depth, although the earthquake with the highest stress drop (no. 7) was the deepest of those analyzed.

Event 6 had by far the highest stress drop of the events studied. It was followed within $1 \mathrm{hr}$ by event 7 just $1.5 \mathrm{~km}$ away. The relative locations of these earthquakes are shown in Figure 12. They were situated near the San Jacinto fault zone, about $10 \mathrm{~km}$ south of the Anza seismic gap (Thatcher et al., 1975) at a depth of about 17 $\mathrm{km}$. Figure 12 also depicts the location of a magnitude 5.5 event that occurred on 25 February 1980. It is interesting to note that this larger shock was positioned only $1.5 \mathrm{~km}$ away from the high stress drop event of 2 July 1979 (event 6), and was produced less than 8 months after it.

Events 6 and 7 represent an important example of two earthquakes in about the same location and with comparable moments that have significantly different stress drops. The waveforms of these two events recorded at four stations at varying azimuths are also displayed in Figure 12. This figure contains the seismograms used 
as the empirical Green's function for both events 6 and 7. For stations PSP, KEE, and COY a small earthquake at 12:14 UTC is displayed as the Green's function. The seismogram shown for this event was processed to remove the effects of the antialiasing filter so that its zero crossing could be compared to that of the clipped records. The waveform of the empirical Green's function illustrated for SMO is the analog record for a small foreshock to event 7 . The clipped records shown are from playbacks of the analog tapes, with no antialiasing filter.

The essential finding conveyed in Figure 12 is that $\tau_{1 / 2}$ for the first event (no. 6 , 11:51 UTC) is significantly shorter than that of the second event (no. 7, 12:42 UTC) at all of the stations that were studied. This observation implies that the rupture duration of event 6 is shorter than that of event 7 . If the rupture velocities of these

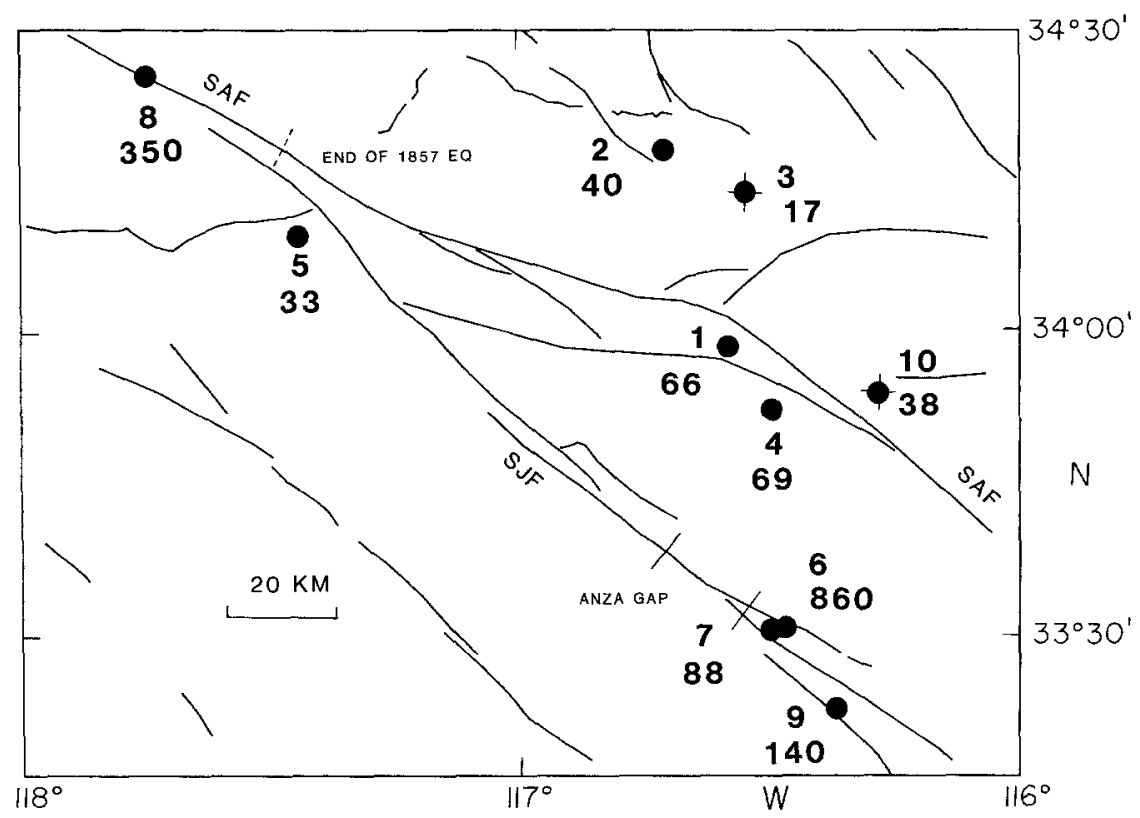

FiG. 11. Map with stress drops and event numbers. Circles with crosses denote events with inferred unilateral rupture. Note the proximity of event 6 with the 860 bar stress drop to event 7 with a 88 bar stress drop.

earthquakes are similar (as we assume), then the fault radius of event 6 is also smaller than event 7 , and its stress drop is higher. The fact that $\tau_{1 / 2}$ was observed to differ at stations at a variety of azimuths implies that there is truly a difference in rupture duration between these events and not just a variation in rupture directivity.

The estimate of how large a difference in stress drop there is between events 6 and 7 is dependent on some of our assumptions. We assume these events have similar rupture velocities, although observationally we cannot constrain this parameter. It is possible that the events we use as empirical Green's functions are not of small enough moment to truly indicate the minimum value of $\tau_{1 / 2}$ for that path. The larger the correction of the pulse width for path effects becomes, the greater the percentage difference in the corrected $\tau_{1 / 2}$ 's. For example, the average uncorrected $\tau_{1 / 2}$ is $0.089 \mathrm{sec}$ for event 6 and $0.113 \mathrm{sec}$ for event 7 . If these uncorrected values of $\tau_{1 / 2}$ are interpreted as the true source duration, then the fault radii for these events 
differ by a factor of 1.3 , and their stress drops differ by a factor of 3.3 . However, after we subtract the values of $\tau_{1 / 2}$ of the empirical Green's function, the $\tau_{1 / 2}$ 's differ by a factor of 1.8 and the stress drops vary by a factor of about 10 . We feel that the path corrections we utilize are justified by the data and that the best estimate of

PSP $33 \mathrm{~km}$
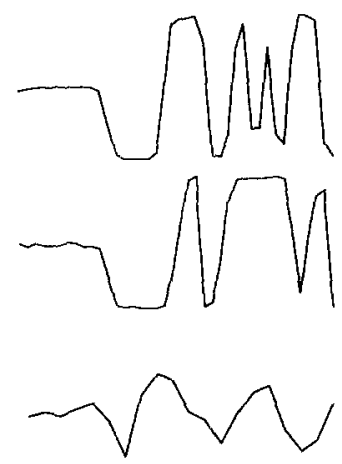

SMO $6 \mathrm{~km}$
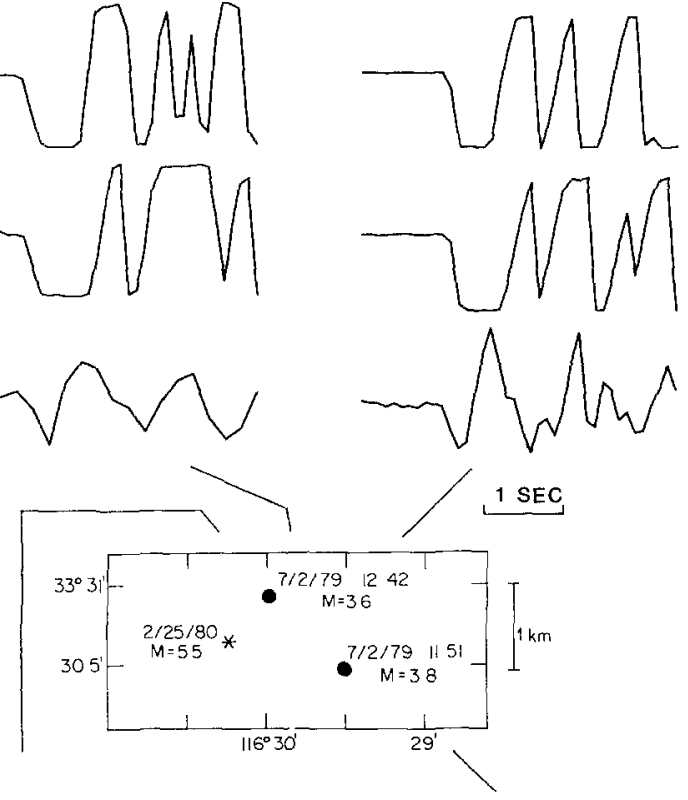

KEE $21 \mathrm{~km}$

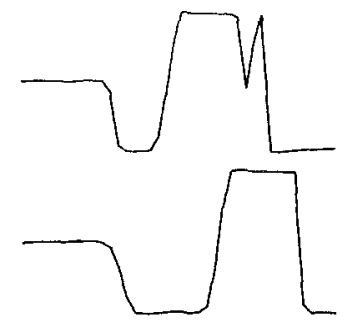

COY $23 \mathrm{~km}$
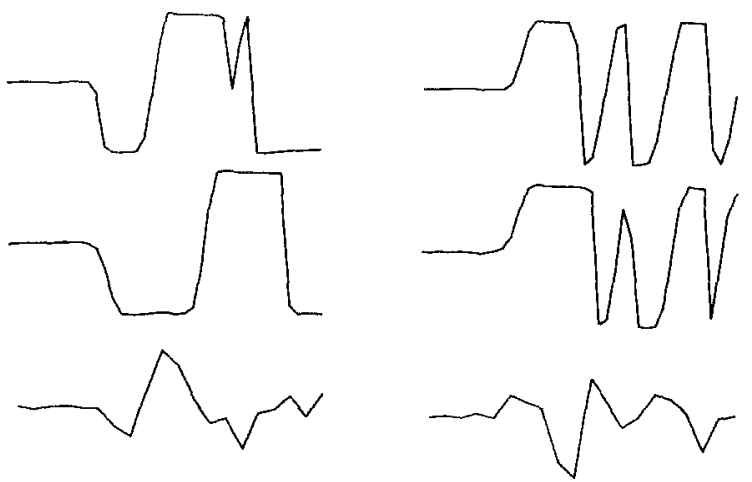

Fig. 12. Map with the positions of events 6 and 7 along the San Jacinto fault zone, along with their seismograms recorded at four stations. The top seismogram for each station is of event 6 (11:51 UTC), the middle seismogram is from event 7 (12.42 UTC), and the bottom record is of a small event used as the empirical Green's function (see text). Lines emanating from the map are initıally oriented at the azımuth between the events and that particular station Note that the time between the $P$-wave onset and the first zero crossing is shorter for event 6 than for event 7 at all of the stations Position of $M_{L} 5.5$ on 25 February 1980 is also shown on the map.

the ratio of stress drops for these events is 10 . This finding indicates that large differences in stress drop can occur over a distance of $1.5 \mathrm{~km}$.

The seismicity associated with the 2 July 1979 sequence is of importance in its relation to the $M_{L} 5.5$ shock which followed. In Figure 13, we show the master event relocations for the events of 2 July 1979. The absolute positions of these events 
vary slightly from those in Figure 12, because a smaller set of stations was used. After the 11:51 event occurred (event 6), a cluster of three small earthquakes was generated well outside of the rupture zone calculated for event 6 . Then the 12:42 earthquake (event 7) occurred about $1 \mathrm{~km}$ to the north of the cluster and $1.5 \mathrm{~km}$ west of event 6 . The hypocenter of the 25 February 1980 , event $\left(M_{L}=5.5\right)$ was located between event 7 and the cluster of events to the south. Aftershock locations of the February 1980 shock indicate that it ruptured unilaterally to the northwest (Sanders and Kanamori, 1983), away from the location of the high stress drop event. This example illustrates the added information that stress drop estimates can contribute to studies of precursory seismicity.

\section{Limitations of THE Method}

There are several limitations to this method of determining rupture duration, some involving the instrumentation and others caused by the variability of the data.

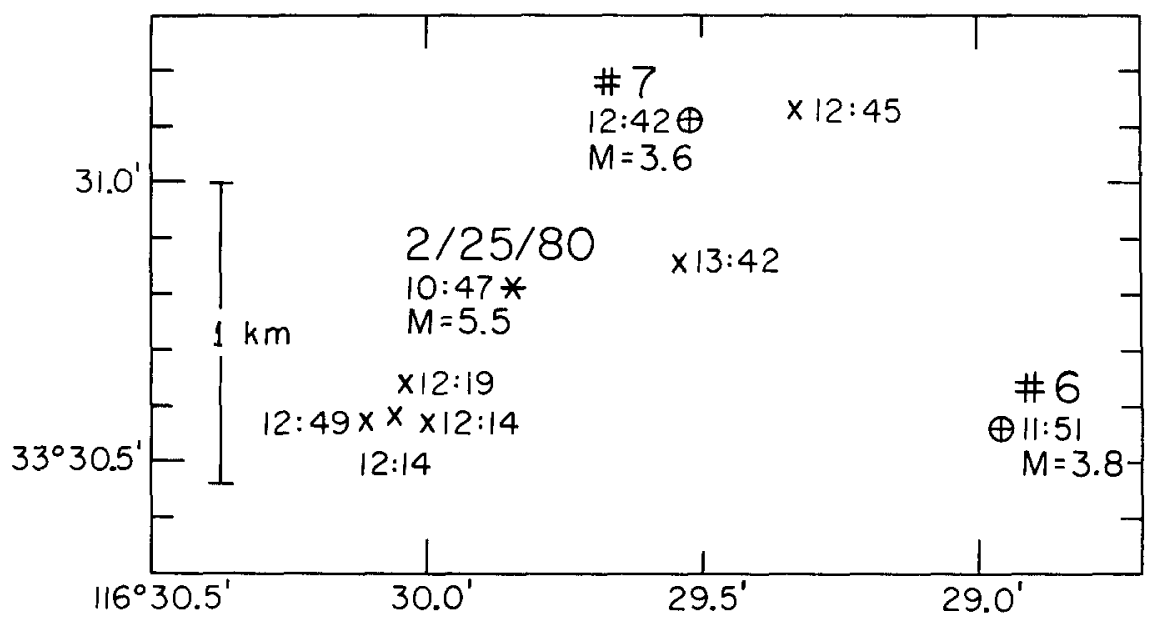

FIG 13 Master event relocations of all of the events that occurred on 2 July 1979 , near the sequence shown in Figure 12. Events are labeled with the origin times in hours and minutes. Circles with crosses denote events 6 and 7 . The location of the 25 February 1980 event $\left(M_{L}=55\right)$ is denoted by an asterisk.

There are indications that, in a few cases, the zero crossing on the clipped record is not accurate. One of the events studied, event 11 , produced a wide range of corrected $\tau_{1 / 2}$ 's at stations with similar azimuths (see Table 1). We did not calculate source parameters for this earthquake. The inconsistency of the pulse widths for event 11 could be a result of unreliable zero crossings at one or two stations. Similarly, the zero crossing for event 7 at station KEE is inconsistent with $\tau_{1 / 2}$ at PSP, which is at about the same azimuth. The corrected value of $\tau_{1 / 2}$ at $\mathrm{KEE}$ for this earthquake is much larger than at the four other stations. The $\tau_{1 / 2}$ residual at KEE determined for event 7 plotted well outside the field observed for the other earthquakes studied and is shown by the circled number in Figure 6.

One problem of this method is whether the waveforms of the aftershocks accurately reflect the minimum values of pulse width for a particular source-receiver pair. In several cases, we do not have a suite of earthquakes in one location with a wide enough range of magnitudes to produce a graph such as those in Figure 3 . The magnitude where the minimum $\tau_{1 / 2}$ is reached varies with the path and may not be attained for some of the sequences studied. 
Small errors in estimating the value of the minimum $\tau_{1 / 2}$ can be important when comparing events from different regions. The variation in the average pulse width between a high stress drop event (e.g., event 6) and a low stress drop one (e.g., event 7 ) is only about $0.02 \mathrm{sec}$. By averaging readings at several stations for each event, we have tried to alleviate this problem. The fact that our corrected values of $\tau_{1 / 2}$ essentially track the original values gives us confidence that errors in estimating the minimum $\tau_{1 / 2}$ have not affected the relative stress drops of these earthquakes.

Of course, the most accurate way to apply this method of determining source duration is to use unclipped records. As network instrumentation with higher dynamic range becomes available, the comparison of the entire waveforms of main shocks and aftershocks will be possible on a routine basis.

\section{Discussion}

The results of this study shown in Figure 11 call attention to regions that deserve further investigation. The stress drop of event 8 was the second highest found ( 350 bars) and was significantly larger than seven of the other earthquakes. This event was located within $3 \mathrm{~km}$ of the surface trace of the San Andreas fault at a depth of $7.2 \mathrm{~km}$. The southern end of the rupture zone of the great 1857 earthquake is situated about $30 \mathrm{~km}$ to the south of this event. The high stress drop of this event may reflect high stresses generated by the locked nature of the San Andreas fault in this area.

Along the San Jacinto fault zone, the difference in stress drop between events 6 and 7 may reflect the heterogeneity of strength along the fault zone on a scale of a few kilometers. It is interesting that event 6 , with the highest stress drop of the earthquakes studied here, apparently triggered event 7 and smaller events in the vicinity (Figure 13). Das and Scholz (1981) proposed that delayed multiple events (such as events 6 and 7) are caused by subcritical crack growth penetrating a high strength barrier along the perimeter of the rupture zone of the initial earthquake after the seismic rupture has been halted. The second event is produced when the subcritical crack reaches a weak area on the other side of the barrier. A high stress drop event (such as event 6 ) would be more likely to trigger secondary events than a low stress drop earthquake since the subcritical rupture growth is dependent on the stress intensity factor at the crack tip which is proportional to the static stress drop of the initial event (see Das and Scholz, 1981).

In conclusion, this paper has demonstrated that important information about the rupture duration and directivity of earthquakes between magnitude 3.5 and 4.0 can be obtained from the zero crossings of clipped records from local seismic networks. This paper has also shown the need for empirical corrections to account for path effects on short-period waveforms. The pulse width of small events varies for sourcereceiver paths of similar distances and cannot be explained by source effects in most instances. The initial pulse widths of small earthquakes $(M<2.5)$ appear in most cases studied to be dominated by path effects even for relatively short distances $(<40 \mathrm{~km})$ between source and receiver.

This study has documented that significant variations in rupture duration and stress drop occur for earthquakes of $M_{L}$ between 3.5 and 4.0 in southern California. Events of this magnitude occur frequently enough so that, over a period of a few years, regional averages of stress drop can be obtained. By applying the technique presented in this paper on a routine basis to a larger set of earthquakes, the variability of stress drop can be assessed and the potential link between high stress drop events and impending larger earthquakes can be evaluated. 


\section{ACKNOWLEDGMENTS}

We thank Tom Heaton for reviewing the manuscript. Jim Pechmann, Mary O'Neill, Carl Johnson, Bill Bakun, and Bill Ellsworth provided useful discussions. Carl Johnson and Bernard Minster wrote the software to access the digital network data. We thank Bill Ellsworth and Jerry Eaton for their help in obtainıng the analog tapes for the southern Calıfornia network. The figures were drafted by Laszlo Lenches. This research was supported by the U.S. Geological Survey under Contract 14-08-0001-21210 One of the authors, (A. F.) was supported by a Bantrell Fellowship.

\section{REFERENCES}

Andrews, D J (1982). Separation of source and propagation spectra of seven Mammoth Lakes aftershocks, Proc of Workshop XVI, The Dynamic Characteristics of Faulting Inferred from Recordings of Strong Ground Motıon, US Geol Surv, Open-Fle Rept 82-591, 437-454.

Archambeau, C. B (1979) Earthquake hazards determmation based on tectonic stress measurements, Semi-Annual Tech Rep 3, U.S Geological Survey Contract No. 14-08-0001-16773, Menlo Park, California.

Archuleta, R. J , E. Cranswick, C. Mueller, and P. Spudich (1982). Source parameters of the 1980 Mammoth Lakes, California, earthquake sequence, J. Geophys Res. 87, 4595-4608

Bakun, W. H , C G Bufe, and R. M. Stewart (1976) Body-wave spectra of central California earthquakes, Bull Selsm Soc Am 66, 363-384.

Ben-Menahem, A. (1962). Radiation of seismic body waves from a finite moving source in the earth, $J$ Geophys Res 67, 345-350

Boatwright, J. (1980). A spectral theory for circular seismic sources, simple estimates of source dimension, dynamic stress drop and radiated seismic energy, Bull Selsm Soc Am 70, 1-28.

Brune, J. N (1970). Tectonic stress and the spectra of seismic shear waves from earthquakes, J. Geophys Res. 75, 4997-5009

Carpenter, E. W (1966). Absorption of elastic waves-An operator for a constant $Q$ mechanism, United Kıngdom Atomic Energy Authority, AWRE Report D-43/66

Cervený, V. (1966). On dynamic properties of reflected and head waves in the $n$-layered earth's crust, Geophys of 11, 139-147.

Das, S. and C. H. Scholz (1981) A theory of time-dependent rupture in the earth, J. Geophys Res 86, 6039-6051

Ellis, J. and A. Lindh (1976) Linearity of VCO-discriminator system with respect to zero crossing times, US Geol Surv, Open-File Rept. 76-873.

Frankel, A. (1982). The effects of attenuation and site response on the spectra of microearthquakes in the northeastern Caribbean, Bull Setsm. Soc. Am. 72, 1379-1402

Hanks, T. C (1982) $f_{\text {max }}$, Bull. Setsm. Soc Am. 72, 1867-1880.

Johnson, C. E (1979). I. CEDAR-An approach to the computer automation of short-period local seismic networks, II Seismotectonics of the Imperial Valley of Southern California, Ph D Thesis, Californı Instıtute of Technology, Pasadena, Calıfornia.

O'Neill, M E. and J. H Healy (1973). Determination of source parameters of small earthquakes from $P$-wave rise time, Bull. Setsm Soc Am. 63, 599-614.

Sanders, C. O. and H. Kanamorı (1983) A seismotectonıc analysis of the Anza seismic gap, San Jacınto fault zone, southern California (preprint).

Sato, T. and T Hirasawa (1973) Body-wave spectra from propagating shear cracks, $J$ Phys. Earth 21, 415-431.

Singh, S K., R. J. Apsel, J. Fried, and J. N. Brune (1982). Spectral attenuation of $S H$ waves along the Imperial fault, Bull Seism Soc. Am. 72, $2003-2016$.

Thatcher, W. and T. C Hanks (1973). Source parameters of southern Calıfornua earthquakes, $J$ Geophys Res 78, 8547-8576

Thatcher, W, J. A. Hileman, and T. C. Hanks (1975). Seısmic slip distribution along the San Jacinto fault zone. Southern Calıfornia and its implicatıons, Geol Soc Am Bull 86, 1140-1146

SEISMOLOGICAL LABORATORY

California Institute of Technology

Pasadena, California 91125

Contribution No. 3880

Manuscrupt received 6 May 1983 